\title{
Stone composition of renal stone formers from different global regions
}

\author{
Adam Halińnki ${ }^{1}$, Kamran Hassan Bhatti ${ }^{2}$, Luca Boeri ${ }^{3}$, Jonathan Cloutier ${ }^{4}$, Kaloyan Davidoff ${ }^{5}$ \\ Ayman Elqady ${ }^{6}$, Goran Fryad ${ }^{7}$, Mohamed Gadelmoula ${ }^{6}$, Hongyi Hui ${ }^{8}$, Kremena Petkova ${ }^{9}$, Elenko Popov ${ }^{5}$, \\ Bapir Rawa ${ }^{10}$, Iliya Saltirov ${ }^{9}$, Francisco R. Spivacow ${ }^{11}$, Belthangady Monu Zeeshan Hameed ${ }^{12}$, \\ Alberto Trinchieri ${ }^{13}$, Noor Buchholz ${ }^{13}$ \\ ${ }^{1}$ Private Medical Center "Klinika Wisniowa" Zielona Gora; Poland; \\ 2 Urology Unit, City Hospital Pakpattan, Pakistan; \\ ${ }^{3}$ Department of Urology, IRCCS Ca' Granda Ospedale Maggiore Policlinico, University of Milan, Milan, Italy; \\ ${ }^{4}$ CHU de Québec, Laval University, Québec City, Canada; \\ ${ }^{5}$ Acibadem City Clinic Tokuda Hospital, Sofia, Bulgaria; \\ ${ }^{6}$ Urology Department, Assiut University, Assiut, Egypt; \\ 7 Shar Teaching Hospital, Sulaymanyah City, Iraq; \\ ${ }^{8}$ Department of Urology, Renji Hospital, Shanghai Jiaotong University School of Medicine, Shanghai, China; \\ ${ }^{9}$ Department of Urology and Nephrology, Military Medical Academy, Sofia, Bulgaria; \\ ${ }^{10}$ Smart Health Tower, Sulaymaniyah, Kurdistan region, Iraq; \\ ${ }^{11}$ Instituto de Investigaciones Metabólicas (IDIM Department of Urology), Buenos Aires, Argentina; \\ 12 Department of Urology, Kasturba Medical College, Manipal, Karnataka, India; \\ ${ }^{13}$ U-merge Ltd (Urology for emerging countries), London, UK.
}

\section{Summary Objective: To study urinary stone composi-} the world.

Materials and methods: Data were collected by reviewing charts of 1204 adult patients of 10 countries with renal or ureteral stones (> 18 years) in whom a stone analysis was done and available. Any method of stone analysis was accepted, but the methodology had to be registered.

Results: In total, we observed 710 (59\%) patients with calcium oxalate, 31 (1\%) with calcium phosphate, 161 (13\%) with mixed calcium oxalate/calcium phosphate, 15 (1\%) with carbapatite, 110 (9\%) with uric acid, 7 (<1\%) with urate (ammonium or sodium), 100 (9\%) with mixed with uric acid/ calcium oxalate, $56(5 \%)$ with struvite and 14 (1\%) with cystine stones. Calciumcontaining stones were the most common in all countries ranging from 43 to $91 \%$. Oxalate stones were more common than phosphate or mixed phosphate/oxalate stones in most countries except Egypt and India. The rate of uric acid containing stones ranged from 4 to 34\%, being higher in Egypt, India, Pakistan, Iraq, Poland and Bulgaria. Struvite stones occurred in less than $5 \%$ in all countries except India (23\%) and Pakistan (16\%). Cystine stones occurred in $1 \%$ of cases.

Conclusions: The frequency of different types of urinary stones varies from country to country. Calcium-containing stones are prevalent in all countries. The frequency of uric acid containing stones seems to depend mainly on climatic factors, being higher in countries with desert or tropical climates. Dietary patterns can also lead to an increase in the frequency of uric acid containing stones in association with high obesity rates. Struvite stones are decreasing in most countries due to improved health conditions.

KEY WORDS: Urinary calculi; Epidemiology; Gender; Age; Calcium oxalate; Calcium phosphate; Uric acid; Struvite; Cystine.

Submitted 18 August 2021; Accepted 25 August 2021

\section{BACKGROUND}

Most data on chemical stone composition have been collected in the Western world (1-8). It is well known that stone composition is dependent on lifestyle and diet, which in turn is dependent on country, climate and culture. Therefore, it is of interest to establish a more globalised map of chemical stone composition around the globe. U-merge, an association gathering urologists from all over the world, is the ideal platform for this task. For this reason, the scientific office of U-Merge launched a study to collect the results of urinary stone analyses among different populations in the countries of its members.

\section{MATERIALS AND METHODS}

All members of U-merge were invited to join in the study. Data were collected by reviewing charts of adult patients (> 18 years) with renal or ureteral stones observed in each participating center who had chemical analysis of the stone available. Gender, age, country and stone composition of each patient were recorded in an Excel data base. Any method of stone analysis was accepted, but the methodology had to be known and registered. A minimum number of 30 patients per center was required. Stones analyzed by wet chemical were classified as calcium oxalate ( $\mathrm{CaOx}$ ) (unspecified), calcium phosphate (CaP) (unspecified), mixed calcium oxalate/calcium phosphate ( $\mathrm{CaOx} / \mathrm{CaP})$, struvite, uric acid (UA), mixed uric acid/calcium oxalate (UA/CaOx) and cystine.

Stones analysed by infrared spectroscopy or X-ray diffractometry were classified as $\mathrm{CaOx}$ dihydrate $(>50 \%), \mathrm{CaOx}$ monohydrate (> 50\%), CaP (> 50\%), mixed CaOx/CaP (if $\mathrm{CaP}>10 \%$ ), struvite (> 50\%), carbonate apatite (50\%), UA anhydrous (> 50\%), UA dihydrate (> 50\%), ammonium

No conflict of interest declared. 


\begin{tabular}{|lcccccccccc}
\hline & Argentina & Bulgaria & Canada & China & Egypt & India & Iraq & Italy & Pakistan & Poland \\
\hline$N^{\circ}$ & 300 & 183 & 50 & 90 & 73 & 35 & 36 & 360 & 44 & 33 \\
\hline $\mathrm{M}$ & $179(59 \%)$ & $122(67 \%)$ & $28(56 \%)$ & $58(64 \%)$ & $57(78 \%)$ & $26(74 \%)$ & $26(72 \%)$ & $226(63 \%)$ & $38(86 \%)$ & $16(48 \%)$ \\
\hline $\mathrm{F}$ & $121(41 \%)$ & $61(33 \%)$ & $22(44 \%)$ & $32(36 \%)$ & $16(22 \%)$ & $9(26 \%)$ & $10(28 \%)$ & $134(37 \%)$ & $6(14 \%)$ & $17(52 \%)$ \\
\hline Age & $45+12$ & $48+13$ & $56+14$ & $50+12$ & $40+12$ & $50+12$ & $38+13$ & $56+14$ & $40+8$ & $50+17$ \\
\hline Agge $p=0.000 ; M / F p=0.002$. & & & & & & & & &
\end{tabular}

Table 1.

Average age and $\mathrm{M} / \mathrm{F}$ ratio of RSFs from different countries. urate (> 50\%), sodium urate (> 50\%), mixed UA/CaOx, cystine.

The Statistical Package for the Social Sciences (SPSS) version 11.5 for Windows was used for statistical analysis. Comparisons were considered to differ significantly if $\mathrm{p}<0.05$

\section{RESULTS}

In total, 1204 renal stone formers (RSFs) were considered (776 males, 428 females) from 10 countries (Argentina, Bulgaria, Canada, China, Egypt, India, Iraq, Italy, Pakistan and Poland).

Twelve institutions from 10 countries have joined the survey as listed below:

- Department of Urology, Instituto de Investigaciones Metabólicas, Buenos Aires (Argentina)

- Acibadem City Clinic Tokuda Hospital, Sofia (Bulgaria)

- Department of Urology and Nephrology, Military Medical Academy, Sofia (Bulgaria)

- CHU de Québec, Laval University, Québec City (Canada)

- Dep of Urolotgy, Renji Hospital, Shanghai Jiaotong University School of Medicine, Shanghai (China)

- Urology Department, Assiut University, Assiut (Egypt)

- Department of Urology, Kasturba Medical College, Manipal, Karnataka (India)

- Urology Department, Sulaymaniyah Surgical Teaching Hospital, Sulaymaniyah (Iraq)

- Shar Teaching Hospital, Sulaymanyah City (Iraq)

- Department of Urology, IRCCS Ca' Granda Ospedale Maggiore Policlinico, Milan (Italy)

- City Hospital Pakpattan, Pakpattan (Pakistan)

- Private Medical Center Klinika Wisniowa, Zielona Gora (Poland)

The average age of patients was $49.3+14.4$ and the $M / F$ ratio was 1.81 . The number, average age and $\mathrm{M} / \mathrm{F}$ ratio of RSFs from different countries are shown in Table 1. The average age of RSFs in Italy and Canada was greater than that of the RSFs of Argentina ( $p=0.000)$, Bulgaria $(\mathrm{p}=0.000$ and $\mathrm{p}=0.001)$, Egypt ( $\mathrm{p}-0.000), \operatorname{Iraq}(\mathrm{p}=$ 0.000 , and Pakistan $(p=0.000)$. The average age of RSFs in Italy was higher than that of the RSFs in China ( $\mathrm{p}=$ 0.011). The lowest average age was observed in Egypt, Iraq, and Pakistan, where the average age of RSFs was lower than those of RSFs in Canada $(p=0.000)$, Italy ( $p=$ $0.000)$ and China ( $p=0.000, p=0.000$ and $p=0.001)$. In Egypt and Iraq, the average age of the RSFs was also lower than in Bulgaria $(\mathrm{p}=0.001, \mathrm{p}=0.002)$, Poland $(\mathrm{p}=$ $0.020, \mathrm{p}=0.007)$ and India $(\mathrm{p}=0.009$ and $\mathrm{p}=0.004)$ The frequency of the disease was slightly higher in women in Poland (52\%), whereas it tended to be higher in men in Canada (56\%), Argentina (59\%), Italy (63\%), China (64\%) and Bulgaria (67\%). Highest rates in men
Table 2.

Spectrum of stone composition by gender and age.

\begin{tabular}{|c|c|c|c|c|c|c|}
\hline & \multicolumn{2}{|c|}{ Gender } & \multicolumn{3}{|c|}{ Age class } & \multirow[b]{2}{*}{ Total } \\
\hline & Males & Females & $18-39$ & $40-59$ & $>60$ & \\
\hline$\overline{\mathrm{CaOx}}$ & $461(59 \%)$ & $249(58 \%)$ & $200(59 \%)$ & $318(57 \%)$ & $192(62 \%)$ & $710(59 \%)$ \\
\hline$\overline{\mathrm{COM}}$ & 223 & 105 & 73 & 136 & 119 & 328 \\
\hline$\overline{C O D}$ & 52 & 23 & 20 & 34 & 21 & 75 \\
\hline$\overline{\mathrm{CaO} / \mathrm{CaP}}$ & $89(11 \%)$ & $72(16 \%)$ & $46(13 \%)$ & $80(14 \%)$ & $35(11 \%)$ & $161(13 \%)$ \\
\hline$\overline{\mathrm{CaP}}$ & $18(2.3 \%)$ & $13(3.0 \%)$ & $12(3.5 \%)$ & $14(2.5 \%)$ & $5(1.5 \%)$ & $31(3 \%)$ \\
\hline$\overline{\text { Carbapatite }}$ & $4(0.5 \%)$ & $11(2.5 \%)$ & $5(1.5 \%)$ & $8(1.5 \%)$ & $2(0.5 \%)$ & $15(1 \%)$ \\
\hline Ca-containing & $572(74 \%)$ & $345(80 \%)$ & $263(77 \%)$ & $420(76 \%)$ & $234(76 \%)$ & $917(76 \%)$ \\
\hline$\overline{U A}$ & $84(11 \%)$ & $26(6 \%)$ & $22(6.4 \%)$ & $49(8.8 \%)$ & $39(12.6 \%)$ & $110(9 \%)$ \\
\hline$\overline{\text { Urate }}$ & $4(0.5 \%)$ & $3(0.7 \%)$ & $0(0 \%)$ & $4(0.5 \%)$ & $3(1 \%)$ & $7(0.5 \%)$ \\
\hline$\overline{\mathrm{UA} / \mathrm{CaOX}}$ & $75(10 \%)$ & $25(6 \%)$ & $25(7 \%)$ & $55(10 \%)$ & $20(6 \%)$ & $110(9 \%)$ \\
\hline UA-containing & $163(21 \%)$ & $54(13 \%)$ & $47(14 \%)$ & $108(19 \%)$ & $62(20 \%)$ & $217(18 \%)$ \\
\hline Struvite & $33(4.2 \%)$ & $23(5.4 \%)$ & $23(7 \%)$ & $22(4 \%)$ & $11(3.5 \%)$ & $56(5 \%)$ \\
\hline$\overline{\text { Cystine }}$ & $8(1.1 \%)$ & $6(1.4 \%)$ & $8(2.5 \%)$ & $4(0.5 \%)$ & $2(0.5 \%)$ & $14(1 \%)$ \\
\hline Total & 776 & 428 & 341 & 554 & 309 & 1204 \\
\hline
\end{tabular}

were observed in Pakistan (86\%), Egypt (78\%), India (74\%) and $\operatorname{Iraq}(72 \%)$.

The spectrum of stone composition by gender and age is shown in Table 2. In total, we observed 710 (59\%) patients with calcium oxalate, 31 (1\%) with calcium phosphate, 161 (13\%) with mixed calcium oxalate/calcium phosphate, 15 (1\%) with carbapatite, 110 (9\%) with uric acid, 7 (<1\%) with urate (ammonium or sodium), 100 (9\%) with mixed with uric acid/ calcium oxalate, 56 (5\%) with struvite and 14 (1\%) with cystine stones.

In the calcium-containing group, calcium oxalate stones accounted for $77 \%$ and phosphate or mixed calcium phosphate/calcium oxalate stones for the remaining 23\%. The frequency of calcium phosphate or mixed calcium phosphate/calcium oxalate ranged from 9 to $74 \%$.

The great variability depends on the different methods of analyzing stones and reporting the results.

In 403 patients with calcium oxalate stones analyzed by infrared spectroscopy, calcium oxalate monohydrate stones (COM) were more frequent than calcium oxalate dihydrate (COD) stones.

Frequency of calcium oxalate stones was equal in women and men (58\% vs 59\%), whereas frequency of uric acid containing stones was lower in women than in men (13\% vs $21 \%$ ) and frequency of calcium phosphate and mixed calcium phosphate/calcium oxalate stones ( $21 \%$ vs $14 \%$ ) and frequency of struvite stones were higher in women. Frequency of COM stones tended to be higher in men than in women (78 vs 71\%) and to increase with age (18$39=78 \%, 40-59=80 \%,>60 \%=85 \%)$. 
Table 3.

Spectrum of stone composition in different countries.

\begin{tabular}{|c|c|c|c|c|c|c|c|c|c|c|c|}
\hline & Argentina & Bulgaria & Canada & China & Egypt & India & Iraq & Italy & Pakistan & Poland & Tot \\
\hline$\overline{\mathrm{CaOx}}$ & $239(80 \%)$ & $97(53 \%)$ & $23(46 \%)$ & $65(72 \%)$ & $12(16 \%)$ & $7(20 \%)$ & $16(44 \%)$ & $214(59 \%)$ & $21(48 \%)$ & $16(49 \%)$ & $710(59 \%)$ \\
\hline$\overline{\mathrm{COM}}$ & - & 79 & - & 49 & 12 & & 11 & 178 & & - & \\
\hline$\overline{C O D}$ & . & 18 & . & 16 & 0 & & 5 & 36 & & . & \\
\hline$\overline{\mathrm{CaO} / \mathrm{CaP}}$ & $12(4 \%)$ & $17(9 \%)$ & $11(22 \%)$ & $11(12 \%)$ & $34(47 \%)$ & $8(23 \%)$ & $7(20 \%)$ & $57(16 \%)$ & $0(0 \%)$ & $4(12 \%)$ & $161(13 \%)$ \\
\hline$\overline{\mathrm{CaP}}$ & $7(2 \%)$ & $0(0 \%)$ & $2(4 \%)$ & $6(7 \%)$ & $0(0 \%)$ & $0(0 \%)$ & 0 & $14(4 \%)$ & $2(4 \%)$ & 0 & $31(3 \%)$ \\
\hline Carbapatite & $0(0 \%)$ & $3(2 \%)$ & $10(20 \%)$ & $0(0 \%)$ & $0(0 \%)$ & $0(0 \%)$ & $2(5 \%)$ & $0(0 \%)$ & $0(0 \%)$ & 0 & $15(1 \%)$ \\
\hline Ca-containing & $258(86 \%)$ & $117(64 \%)$ & $46(92 \%)$ & $82(91 \%)$ & $46(63 \%)$ & $15(43 \%)$ & $25(69 \%)$ & $285(79 \%)$ & $2352 \%$ & $2061 \%$ & $917(76 \%)$ \\
\hline$\overline{0 x \%}$ & $92 \%$ & $85 \%$ & $50 \%$ & $79 \%$ & $26 \%$ & $46 \%$ & $64 \%$ & $72 \%$ & $91 \%$ & $80 \%$ & $77 \%$ \\
\hline UA pure & $27(9 \%)$ & $8(4.5 \%)$ & $1(2 \%)$ & $5(5 \%)$ & $0(0 \%)$ & $5(14 \%)$ & $8(22 \%)$ & $39(10.5 \%)$ & $11(25 \%)$ & $6(18 \%)$ & $110(9 \%)$ \\
\hline UA urate & $0(0 \%)$ & $6(3.5 \%)$ & $0(0 \%)$ & $0(0 \%)$ & $0(0 \%)$ & $0(0 \%)$ & $0(0 \%)$ & $1(0.5 \%)$ & $0(0 \%)$ & $0(0 \%)$ & $7(1 \%)$ \\
\hline$\overline{\mathrm{UA} / \mathrm{CaOX}}$ & $6(2 \%)$ & $39(21 \%)$ & $1(2 \%)$ & $1(1 \%)$ & $22(30 \%)$ & $7(20 \%)$ & $1(3 \%)$ & $18(5 \%)$ & $0(0 \%)$ & $5(15 \%)$ & $100(8 \%)$ \\
\hline UA - containing & $33(11 \%)$ & $5329 \%$ & $2(4 \%)$ & $66 \%$ & $22(30 \%)$ & $12(34 \%)$ & $9(25 \%)$ & $58(16 \%)$ & $11(25 \%)$ & $11(33 \%)$ & $217(18 \%)$ \\
\hline Struvite & $9(3 \%)$ & $10(5.4 \%)$ & $1(2 \%)$ & $2(3 \%)$ & $4(5.5 \%)$ & $8(23 \%)$ & $1(3 \%)$ & $12(3,5 \%)$ & $8(18 \%)$ & $1(3 \%)$ & $56(5 \%)$ \\
\hline Cystine & $0(0 \%)$ & $3(1.6 \%)$ & $1(2 \%)$ & $0(0 \%)$ & $1(1.5 \%)$ & $0(0 \%)$ & $1(3 \%)$ & $5(1.5 \%)$ & $2(5 \%)$ & $1(3 \%)$ & $14(1 \%)$ \\
\hline Total & 300 & 183 & 50 & 90 & 73 & 35 & 36 & 360 & 44 & 33 & 1204 \\
\hline
\end{tabular}

Frequency of uric acid stones was higher in males and tended to increase with age.

The distribution of the different types of stones in RSFs in different countries is described in Table 3. Calcium-containing stones were the most common in all countries. Among calcium-containing stones, calcium oxalate stones were more frequent in all countries except in Egypt and India where the frequency of calcium phosphate or mixed calcium phosphate/calcium oxalate was 74\% in Egypt and $53 \%$ in India, respectively. Among calcium oxalate stones, the rate of COM stones was 100\% in Egypt, 83\% in Italy, $81 \%$ in Bulgaria, $75 \%$ in China, and $69 \%$ in Iraq. The rate of uric acid containing stones ranged 4 to $34 \%$ in most countries with the highest rates observed in Egypt, India, Poland, and Bulgaria. Struvite stones were less than 5\% in all countries but India (23\%) and Pakistan (16\%). Cystine stones were less than $2 \%$.

\section{Discussion}

\section{Stone composition by age and sex}

In the present study, calcium-containing stones were the most frequent, followed by uric acid-containing stones, while struvite and cystine are less frequent.

In accordance with previous reports (9), uric acid containing stones were more frequent in males and in older ages, whereas phosphate stones were more frequent in women.

The average age of RSFs in different countries varies but these differences reflect those that are observable in the general population of their countries, which averaged about 20 years lower (Figure 1 ).

$\mathrm{M} / \mathrm{F}$ ratio is different in countries, being balanced between men and women or slightly in favor of men in the countries of North America, Europe, South America and China but heavily weighted in favor of men in Egypt, Pakistan, India and Iraq. This finding confirmed the tendency to an increase of stone formation in women of Western countries (9), and more recently of China (10), while in Egypt, Pakistan, India and Iraq the ratio of males to females is still similar to what was observed in Western countries forty years ago (11). This trend can be explained by the so-called nutrition transition, that is the change in dietary habits across the world with a convergence towards an increased consumption of unhealthy

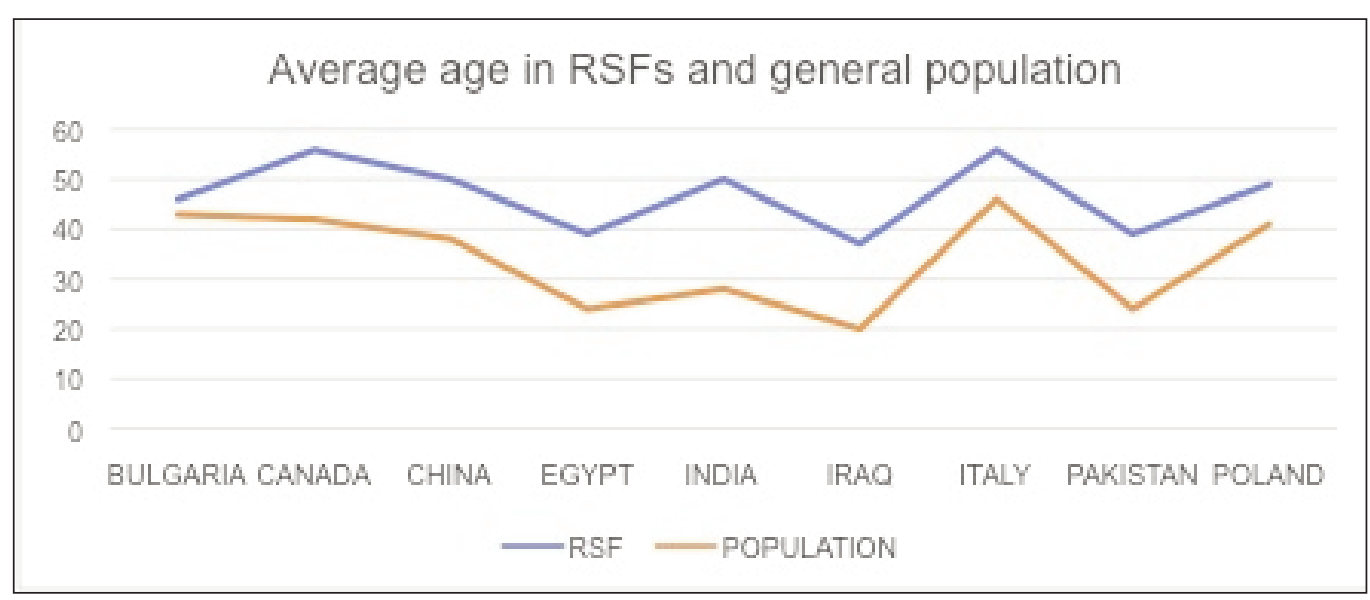

Figure 1. Average age in RSFs and general population. 
foods that is the cause of the increase in non-communicable diseases in almost all regions of the world in both sexes (12). Consumption of unhealthy foods is still limited in some regions of North Africa and South Asia that maintain dietary patterns with a lower risk of urinary stones forming. Moreover, in some countries the characteristics of family structure and cultural rules still present a nutritional disadvantage for women (13).

\section{Stone composition by country}

The spectrum of composition of urinary stones is quite variable in different countries. Differences could be attributable to the different characteristics by age and gender of the populations studied, reflecting the distribution by age and gender in the general population of each country. On the other hand, the modality of stone analysis and reporting in the different centers may be a confounding factor (14). For this reason, the most robust data are those com-

\section{Table 4.}

Mean temperature, precipitation fall and climate classification in the countries involved in the study.

\begin{tabular}{|lccccc|}
\hline Country & Town & $\begin{array}{c}\text { Temperature } \\
\text { mean }\end{array}$ & $\begin{array}{c}\text { Precipitation } \\
\text { fall }\end{array}$ & Climate & $\begin{array}{c}\text { Köppen-Geiger climate } \\
\text { classification system }\end{array}$ \\
\hline Argentina & Buenos Aires & $16.8^{\circ} \mathrm{C}$. & $1040 \mathrm{~mm}$ & Warm temperate & Cfa \\
\hline Bulgaria & Sofia & $10.2^{\circ} \mathrm{C}$ & $581 \mathrm{~mm}$ & Warm temperate & Cfb \\
\hline Canada & Quebec & $4.8^{\circ} \mathrm{C}$. & $1101 \mathrm{~mm}$ & Cold temperate & Dfb \\
\hline China & Shanghai & $16.1^{\circ} \mathrm{C}$ & $1066 \mathrm{~mm}$ & Warm temperate & Cfa \\
\hline Egypt & Asyut & $22.6^{\circ} \mathrm{C}$ & $2 \mathrm{~mm}$ & Hot desert & BWh \\
\hline India & Karnataka & $26.7^{\circ} \mathrm{C}$ & $4866 \mathrm{~mm}$ & Tropical & Am \\
\hline Pakistan & Pakpattan & $24.8^{\circ} \mathrm{C}$ & $234 \mathrm{~mm}$ & Hot desert & BWh \\
\hline Iraq & Sulaymaniyah & $16.2^{\circ} \mathrm{C}$ & $906 \mathrm{~mm}$. & Warm temperate & $\mathrm{Csa}$ \\
\hline Italy & Milan & $13.1^{\circ} \mathrm{C}$ & $1013 \mathrm{~mm}$ & Warm temperate & $\mathrm{Cfa}$ \\
\hline Poland & Zielona Gora & $8.8^{\circ} \mathrm{C}$ & $572 \mathrm{~mm}$ & Warm temperate & $\mathrm{Cfb}$ \\
\hline
\end{tabular}

Figure 2.

Rate of uric-acid containing stones and mean temperature.

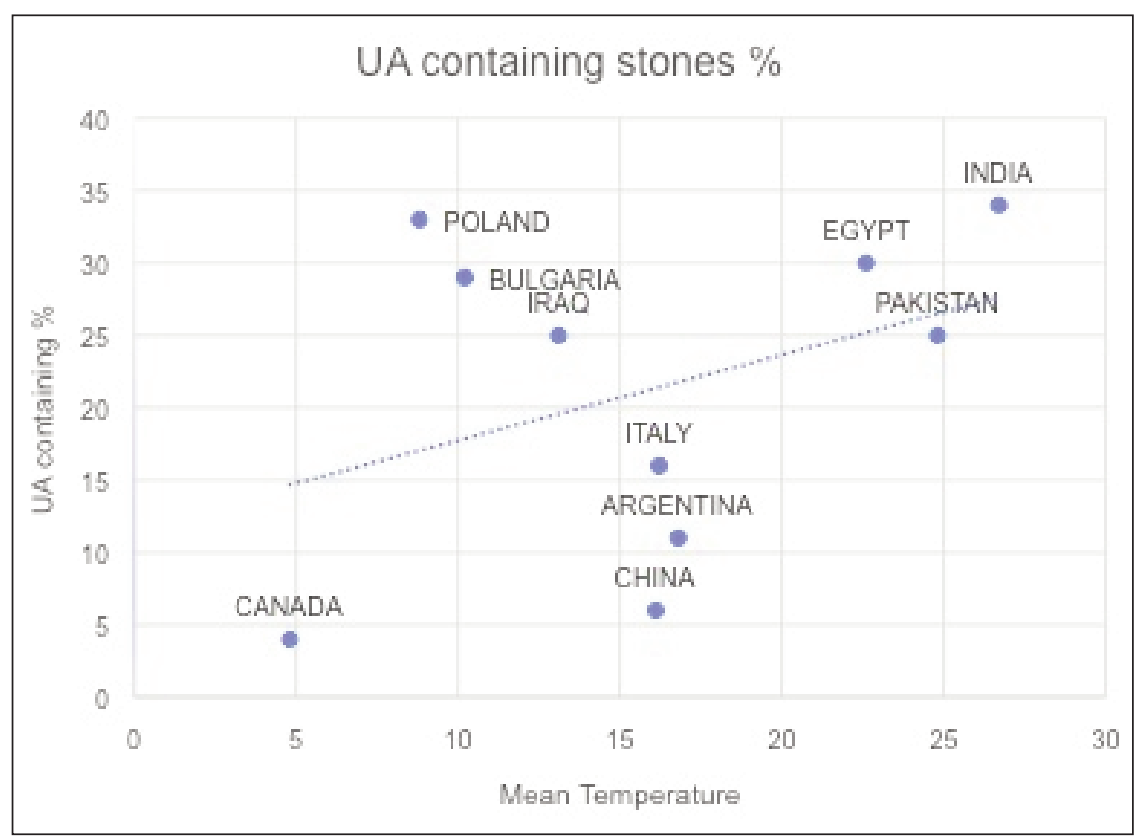

paring the rates of calcium-containing with those of uric acid containing stones, whereas it is less significant to compare the results of different countries in relation to the specific crystallographic composition, which should be compared between patients whose stones have been analyzed and reported in the same laboratory.

Calcium-containing stones were the most common in vast majority of countries with a rate ranging from 52 to 91\%. The highest rates of calcium-containing stones were observed in North America, South America, China and some European countries. In most countries, calcium oxalate stones (in particular, COM stones) were the more frequent calcium-containing stones, although calcium phosphate and mixed calcium oxalate/calcium phosphate stones were more frequent than pure calcium oxalate stones in some countries such as Egypt and India. This trend agrees with previous observation in North America where a tendency has been reported of an increase in oxalate stones and a decrease in phosphate stones during the last two decades $(4,5)$.

The highest rates of acid uric containing stones were observed in Iraq, Pakistan, India, Egypt and Poland and Bulgaria. In general, uric acid-containing stones should be more frequent in older male patients, but surprisingly in our study the highest rates of uric acid-containing stones were observed in two countries with the lowest mean age, namely Egypt and Iraq. This result can be explained by the finding that the frequency of a type of stone is not a measure of the prevalence of the disease in the population, but is the result of the prevalence of different types of urinary stones. In other words, a high frequency of uric acid stones may be due to an increase in the prevalence of uric acid stones but, alternatively, a lower prevalence of other types of stones in the population studied. On the other hand, the impact of environmental factors could be decisive, considering that high temperatures and high humidity cause a decrease of urinary volumes and urinary $\mathrm{pH}$ values resulting in an increase of urinary uric acid saturation and of the incidence of uric acid stones $(15,16)$. In fact, the highest values of uric acid-containing stones were observed in countries with high mean temperatures (17) and tropic or hot desert climates such as Egypt, India, Pakistan and Iraq (Table 4) (Figure 2). Our data confirm previous evidence in the literature showing a high rate of uric acidcontaining stones in Pakistan, Egypt, and Iraq (18-21). In the present 
study, the prevalence of uric acid containing stones was also high in Southern India in accordance with previous reports. In fact, the frequency of uric acid-containing stones was reported low $(4.28 \%)$ or very low $(<1 \%)$ in North Western India $(22,23)$, but higher in Southern India (24). This difference can be explained by different regional eating habits: in the Northern and Western regions, a more traditional vegetarian diet is consumed with exclusive consumption of fruit, vegetables and legumes, whereas in the Southern regions the consumption of sweets, snacks and pork meat is common (25). On the other hand, in our study the lowest rate of uric acid containing stones was observed in Canada, the country with the lowest mean temperature. Intermediate rate values were observed in countries with a temperate climate, such as China and Italy. The high frequency of uric acid-containing stones in Poland is less easily explained, mainly because it contrasts with previous findings showing lower rates of uric acid stones in a series of stones analyzed by infrared spectroscopy (26). Possible explanations are high obesity rate of the population (45\%) and unfavorable dietary patterns (27). In fact, the adherence to the traditional Polish dietary pattern, characterized by high intake of refined grains, potatoes, sugar and sweets is associated with a higher risk of abdominal obesity and hypertriglyceridemia (28). Similarly, in Bulgaria the frequency of uric acid-containing stones is associated with obesity rates which are among the highest in Europe (46\%) (27), and with an unhealthy nutritional pattern characterized by high consumption of fatty meats and meat products, highfat milk and a high alcohol intake (29).

The rate of struvite stones is generally lower than described in the past, due to improved health conditions and early diagnosis and treatment of urinary tract infections by urease-producers, although in some countries such as Pakistan and India it still accounts for a quarter of cases. Cystine stone rates are similar in all countries, with similar rates than those reported in the literature. In conclusion, the frequency of different types of urinary stones varies from country to country. Calcium-containing stones are the most frequent in all countries, with frequencies of up to $90 \%$. The frequency of uric acid containing stones seems to depend mainly on climatic factors, being more frequent in warmer countries with desert or tropical climates although dietary patterns can also lead to an increase in the frequency of uric acid containing stones in association with high obesity rates. Struvite stones are decreasing in most countries except India and Pakistan.

\section{REFERENCES}

1. Daudon M, Donsimoni R, Hennequin C, et al. Sex- and age-related composition of 10617 calculi analyzed by infrared spectroscopy. Urol Res. 1995; 23:319-26.

2. Trinchieri A, Rovera F, Nespoli R, Currò A. Clinical observations on 2086 patients with upper urinary tract stone. Arch Ital Urol Androl. 1996; 68:251-62.

3. Knoll T, Schubert AB, Fahlenkamp D, et al. Urolithiasis through the ages: data on more than 200,000 urinary stone analyses. J Urol. 2011 Apr;185(4):1304-11. doi: 10.1016/j.juro.2010.11.073.

4. Gault MH, Chafe L. Relationship of frequency, age, sex, stone weight and composition in 15,624 stones: comparison of resutls for 1980 to 1983 and 1995 to 1998. J Urol. 2000; 164:302-7.

5. Moses R, Pais VM Jr, Ursiny M, et al. Changes in stone composition over two decades: evaluation of over 10,000 stone analyses. Urolithiasis. 2015; 43:135-9.

6. Singh P, Enders FT, Vaughan LE, et al. Stone composition among first-time symptomatic kidney stone formers in the community. Mayo Clin Proc. 2015; 90:1356-65.

7. Xu LHR, Adams-Huet B, Poindexter JR, et al. Temporal changes in kidney stone composition and in risk factors predisposing to stone formation. J Urol. 2017; 197:1465-1471.

8. Kittanamongkolchai W, Vaughan LE, Enders FT, et al. The changing incidence and presentation of urinary stones over 3 decades. Mayo Clin Proc. 2018; 93:291-299.

9. Lieske JC, Rule AD, Krambeck AE, et al. Stone composition as a function of age and sex. Clin J Am Soc Nephrol. 2014; 9:2141-6. doi: 10.2215/CJN.05660614.

10. Zeng G, Mai Z, Xia S, et al. Prevalence of kidney stones in China: an ultrasonography based cross-sectional study. BJU Int. 2017; 120:109-116. doi: 10.1111/bju.13828. Epub 2017 Mar 21.

11. Johnson CM, Wilson DM, O'Fallon WM, et al. Renal stone epidemiology: a 25-year study in Rochester, Minnesota. Kidney Int. 1979; 16:624-31.

12. Imamura F, Micha R, Khatibzadeh S, et al. Global Burden of Diseases Nutrition and Chronic Diseases Expert Group (NutriCoDE) Dietary quality among men and women in 187 countries in 1990 and 2010: a systematic assessment. Lancet Glob Health. 2015; 3:e132-42.

13. Rao T, E Pingali P. The role of agriculture in women's nutrition: Empirical evidence from India. PloS one 2018; 13:e0201115.

14. Siener R, Buchholz N, Daudon M, et al. Quality Assessment of Urinary Stone Analysis: Results of a Multicenter Study of Laboratories in Europe. PloS one 2016; 11:e0156606.

15. Stuart RO $2^{\text {nd }}$, Hill K, Poindexter J, Pak CY. Seasonal variations in urinary risk factors among patients with nephrolithiasis. J Lithotr Stone Dis. 1991; 3:18-27.

16. Baker PW, Coyle P, Bais R, Rofe AM. Influence of season, age, and sex on renal stone formation in South Australia. Med J Aust. 1993; 159:390-2.

\section{7. https://it.climate-data.org/}

18. Rafique M, Bhutta RA, Rauf A, Chaudhry IA. Chemical composition of upper renal tract calculi in Multan. J Pak Med Assoc. 2000; 50:145-8.

19. Sheir KZ, Mansour O, Madbouly K, et al. Determination of the chemical composition of urinary calculi by noncontrast spiral computerized tomography. Urol Res. 2005; 33:99-104

20. Afaj AH, Sultan MA. Mineralogical composition of the urinary stones from different provinces in Iraq. Scientific World Journal. 2005; 5:24-38

21. Popov E, Almusafer M, Belba A, et al. Obesity rates in renal stone formers from various countries. Arch Ital Urol Androl. 2021; 93:189-194.

22. Bhat A, Singh V, Bhat $M$, et al. Spectrum of urinary stone composition in Northwestern Rajasthan using Fourier transform infrared spectroscopy. Indian J Urol. 2018; 34:144-148. doi: 10.4103/ iju.IJU_363_16.

23. Ansari MS, Gupta NP, Hemal AK, et al. Spectrum of stone composition: structural analysis of 1050 upper urinary tract calculi from northern India. Int J Urol. 2005; 12:12-6. 
24. Marickar YMF. Epidemiology of stone disease in Kerala, South India. In Talati J, Tiselius H-G, Albala DM, Ye Z (eds.) Urolithiasis: basic science and clinical practice, Springer Verlag, London, pp 47-51.

25. Green R, Milner J, Joy EJ, et al. Dietary patterns in India: a systematic review. Br J Nutr. 2016; 116:142-8. doi: 10.1017/ S0007114516001598.

26. Wrobel A, Rokita E, Taton G, Thor P. Chemical composition and morphology of renal stones. Folia Med Cracov. 2013; 53:5-15.
27. Kotseva K, Wood D, De Bacquer D, et al. A European Society of Cardiology survey on the lifestyle, risk factor and therapeutic management of coronary patients from 24 European countries. Eur J Prev Cardiol. 2016; 23:636-48. doi: 10.1177/2047487315569401.

28. Suliga E, Kozieł D, Ciesla E, et al. Dietary patterns in relation to metabolic syndrome among adults in Poland: a cross-sectional study. Nutrients. 2017; 9. pii: E1366. doi: 10.3390/nu9121366.

29. ncpha.government.bg/files/hranene-en.pdf

\section{Correspondence}

Adam Halinski, MD

adamhalinski@gmail.com

Private Medical Center "Klinika Wisniowa"

Anieli Krzywon street 2; 65-001 Zielona Gora (Poland)

Kamran Hassan Bhatti, MD

kamibhatti92@gmail.com

City Hospital Pakpattan (Pakistan)

Luca Boeri, MD

dr.lucaboeri@gmail.com

Department of Urology, IRCCS Ca' Granda Ospedale Maggiore Policlinico

University of Milan, Milan, Italy

Kaloyan Davidoff, MD

shennyp@yahoo.com

Elenko Popov, MD

shennyp@yahoo.com

Acibadem City Clinic Tokuda Hospital - Sofia, Bulgaria

Sofia, bul N. Vaptzarov 51 B

Ayman Elqady, MD

Mohamed Gadelmoula, MD

mgad73@aun.edu.eg

Urology Department - Assiut University - Assiut (Egypt)

Goran Fryad, MD

goranfryad@yahoo.com

Shar Teaching Hospital - Malik Mahmood Circle street, Sulaimani City (Kurdistan Region-Iraq)

PO Box: Baxtyary 36B

Hongyi Hui, MD

1095340463@qq.com

Department of Urology, Renji Hospital, Shanghai Jiaotong University School of Medicine

No.160, Pujian Road, Shanghai, 200127, China

Kremena Petkova, MD

dr_petkova@yahoo.com

Iliya Saltirov, MD

saltirov@vma.bg

Department of Urology and Nephrology, Military Medical Academy

3, Georgi Sofiiski blvd, 1606 Sofia, Bulgaria

Bapir Rawa, MD

dr.rawa@yahoo.com

Smart Health Tower, Sulaymaniyah, Kurdistan region, Iraq

Francisco R Spivacow, MD

frspivacow@gmail.com

Instituto de Investigaciones Metabólicas (IDIM)

Libertad 836, $1^{\circ}$ piso, Ciudad Autónoma de Buenos Aires (Argentina)

Belthangady Monu Zeeshan Hameed, MD

zeeshanhameedbm@gmail.com

Kasturba Medical College, Manipal

Department of Urology, KMC Hospital, Manipal-576104, Karnataka, India

Alberto Trinchieri, MD

alberto.trinchieri@gmail.com

Noor Buchholz, MD (Corresponding Author)

noor.buchholz@gmail.com

U-merge Ltd. (Urology for emerging countries), London, UK 